\title{
ENTRE(VISTAS): Da implicação aos saberes e conhecimentos sobre o ensinar e a inclusão escolar
}

\author{
Carla Helena Fernandes \\ Laura Noemi Chaluh ${ }^{(*)}$
}

\section{INTRODUÇÃO}

A inclusão escolar de alunos que na escola têm necessidades educacionais especiais decorrentes de deficiências, transtorno global do desenvolvimento e superdotação ${ }^{1}$ ainda se coloca como um desafio aos professores que, para além de uma imposição legal, percebem-se mobilizados pelo que ainda precisa ser construído. O processo de mudanças implica na reorganização e na ressignificação dos saberes e conhecimentos ${ }^{2}$ dos docentes (MOTA, 2005; TOBIAS, 2015), o que tem se dado por meio de processo que é complexo. Implica, para os professores, abandonar certezas e reconstruir o que já sabiam, sendo que se indica, para tal, a revisão das concepções e práticas de ensinar visando ao aprendizado desses alunos.

Este texto tem como referência pesquisa realizada junto a professores dos anos finais do ensino fundamental que atuam em 24 escolas da rede estadual de ensino de Minas Gerais, localizadas em um distrito e em dezoito municípios do sul desse Estado. ${ }^{3}$ A pesquisa, de abordagem

\footnotetext{
${ }^{(*)}$ Carla Helena Fernandes. Professora do Mestrado em Educação da Universidade do Vale do Sapucaí (UNIVÁS), em Pouso Alegre - MG; doutorado em Educação pelo Programa de Pós-graduação da Faculdade de Educação da Unicamp. E-mail: carlahelenafernandes@yahoo.com.br.

Laura Noemi Chaluh. Mestre (2002) e doutora (2008) em Educação pela Faculdade de Educação da Universidade Estadual de Campinas (Unicamp). Professora assistente do Departamento de Educação na Universidade Estadual Paulista (IB, Rio Claro). E-mail: chaluh@uol.com.br.

${ }^{1}$ O documento "Política Nacional de Educação especial na perspectiva da educação inclusiva" (BRASIL, 2008) faz uso da expressão "público-alvo da Educação Especial na Educação Básica”, porém, neste texto (e na pesquisa que lhe deu origem) empregamos "alunos que têm necessidades educacionais especiais", uma vez que, focando as práticas pedagógicas e o ensino desenvolvido para esses alunos, propomos reflexões sobre o atendimento de suas necessidades educacionais e o reconhecimento de suas potencialidades. Consideramos essas necessidades educacionais especiais decorrentes de deficiências, transtorno global do desenvolvimento ou superdotação.

${ }^{2}$ Tobias (2015), a partir de Tardif (a obra citada pela autora é a de 2000), discute a definição e a diferenciação entre saberes e conhecimentos. Para essa autora, os saberes são resultantes de um processo histórico do qual participam e estão implicados tanto as experiências docentes como os conhecimentos a que os professores têm acesso. Assim, entende-se os saberes no sentido amplo, "que engloba os conhecimentos, as competências as habilidades (ou aptidões) e as atitudes, isto é, aquilo que muitas vezes foi chamado de saber, saber-fazer e saber-ser" (TARDIF, 2000 apud Tobias, 2015, p. 52). Também Mota (2005) apresenta discussão sobre o assunto. Neste texto, a partir desses estudos anteriores, fazemos uso de "saberes e conhecimentos".

${ }^{3}$ Essas escolas pertencem à Superintendência Regional de Ensino de Pouso Alegre - MG.
} 
qualitativa (BOGDAN; BIKLEN, 1994), se dirigiu às práticas de ensinar desses professores em turmas em que estão matriculados alunos que têm necessidades educacionais especiais; a formação docente também foi objeto de investigação. A pesquisa caracterizou-se como estudo exploratóriodescritivo e fez uso dos seguintes procedimentos e instrumentos: (1) elaboração de um questionário (respondido por 201 professores); (2) entrevista com um grupo menor de participantes (dezoito docentes); 3. construção do diário de campo e do diário fotográfico.

Neste texto socializamos um recorte da referida pesquisa cujo foco está nas entrevistas realizadas ${ }^{4}$. Apresenta-se uma discussão sobre esse processo e algumas questões que se colocam são: as entrevistas podem mesmo constituir-se em situações de reflexão sobre a prática docente? Realizadas entre sujeitos (pesquisadora e professora) que atuaram/atuam na mesma área da qual falam na entrevista, o que se apreende desse mundo de que fala o outro quando se tem experiências semelhantes? Que reflexões são possibilitadas e em que medida podem dar outro sentido aos saberes e conhecimentos dos participantes? Compreende-se que a busca por respostas a essas questões pode ampliar reflexões acerca da entrevista como prática da pesquisa em educação. Na pesquisa apresentada neste texto, as entrevistas foram desenvolvidas buscando-se pela construção de narrativas, como será apresentado na sequência.

\section{A ENTREVISTA COMO UM PROCEDIMENTO DE PESQUISA: INTERAÇÃO E REFLEXÕES}

Nessa pesquisa as entrevistas foram pensadas e desenvolvidas na interface da ideia de entrevista qualitativa, segundo Gaskell (2008), e de entrevista narrativa, na concepção de Jovchelovitch e Bauer (2008) e de Meireles (2015). Além desses autores, visando refletir sobre o que se estabeleceu durante as entrevistas, a leitura de Amorim (2001) foi fundamental para compreender o encontro entre a pesquisadora e as professoras, sobretudo em relação ao lugar da pesquisadora e seus saberes/conhecimentos nesse processo. Da mesma forma, a leitura dos trabalhos de Tobias (2015) e Mota (2005) propiciaram pensar acerca dos saberes da docência e de sua constituição em interação, e o de Chaluh (2008) contribuiu na compreensão da escola como lugar em que se aprende, também a pesquisar.

Para Gaskell (2008), relacionada de forma ampla às ciências sociais empíricas, a entrevista, no interior da pesquisa qualitativa, se define como um "procedimento em que se fazem perguntas,

\footnotetext{
4 Das dezoito entrevistas realizadas apresentamos trechos de duas delas por julgarmos que as mesmas são representativas dos aspectos que se objetivou evidenciar neste texto. Porém, é preciso ressaltar que nossas reflexões têm na sua base o que, de forma geral, se levantou com a totalidade das entrevistas realizadas.
} 
dentro de um período relativamente limitado" (p. 64). Porém, de tipo semiestruturado (individual ou em grupo), essa forma de entrevista é explicada como "uma técnica ou método para estabelecer ou descobrir que existem perspectivas, ou pontos de vista sobre os fatos, além daqueles da pessoa que inicia a entrevista" (FARR, $1982^{5}$ apud GASKELL, 2008, p. 65), perspectiva em que se considera o mundo social do respondente para o encaminhamento do processo de investigação.

Reconhecer e refletir sobre o mundo social do outro (respondente, participante da pesquisa) implica, para o pesquisador, ver-se fora desse outro por ocupar o seu próprio lugar no mundo (social e discursivo). Porém, é no reconhecimento dessas diferenças que reside a possibilidade de encontros entre esses sujeitos e seus saberes.

Sobre a entrevista enquanto uma narrativa, Jovchelovitch e Bauer (2008 e Meireles (2015), pesquisadores cujas reflexões advêm de distintas experiências de pesquisa,se apóiam no estudo do próprio gênero para, a partir daí, projetá-lo como um procedimento de pesquisa, o que vem se afirmando na última década. Para esses autores as narrativas produzem sentidos na interação entre quem narra e quem ouve e, além disso, esses sentidos são mais reconhecíveis para interlocutores de uma mesma comunidade, grupo social ou subcultura. Narrar, para esses autores, é também ouvir-se: "através das narrativas as pessoas lembram o que aconteceu, colocam a experiência em uma sequência, encontram possíveis explicações para isso, e jogam com a cadeia de acontecimentos que constroem a vida individual e social (JOVCHELOVITCH; BAUER, 2008, p. 91).

Em substituição ao esquema pergunta-resposta, na entrevista narrativa, "o pressuposto subjacente é que a perspectiva do entrevistado se revela melhor nas histórias onde o informante está usando a própria linguagem espontânea na narração dos acontecimentos” (JOVCHELOVITCH; BAUER, 2008, p. 96).Porém, para esses autores, a narração que propicia a liberdade do contar a partir do próprio ponto de vista, é um gênero formalmente estruturado e são justamente "as exigências das regras tácitas que libertam o contar histórias" (p. 96). Nesse sentido, também a entrevista narrativa precisa se basear em regras sobre "como ativar o esquema da história; como provocar narrações dos informantes; e como, uma vez começada a narrativa, conservar a narração andando através da mobilização do esquema autogerador" (p. 96).

Também com referência na potência da narrativa enquanto prática social e discursiva, Meireles (2015) faz uso da abordagem (auto)biográfica afirmando que essa "possibilita aos professores se posicionarem frente às suas trajetórias, sobre o que conhecem e fazem, o que fizeram

\footnotetext{
${ }^{5}$ FARR, R. M. Interviewing: the Social Psychology of the interview. In: FRANSELLA, F. Psychology for Occupational Therapists. London: Macmillan, 1982.
} 
e podem vira fazer" (p. 285). Relacionado passado, presente e futuro a narrativa e a pesquisa (auto)biográfica podem propiciar aos professores "compreender os sentidos que atribuem à profissão, constituir um inventário de experiências profissionais vivenciadas, ao mesmo tempo e mais global da pessoa" (p. 287).Pode, assim, ser promotora do caminhar para si propiciado pelo falar de si ao outro (JOSSO, 2010 apud MEIRELES, 2015, p. 287), o que pode ser entendido como um processo de reflexão.

A partir de estudo realizado com professores da educação básica, Tobias (2015) nos fala acerca de entrevistas como situações que podem propiciar a reflexão sobre a prática docente. Nesse processo, está presente um movimento de identificação ou de diferenciação entre pesquisador e professores participantes da pesquisa.

Tobias (2015), que também atuava como professora na mesma escola e no mesmo nível de ensino dos professores participantes da sua pesquisa, inspirada no livro "Castelo dos Destinos Cruzados", de Ítalo Calvino, ${ }^{6}$ diz da emergência de sentidos a partir da fala dos professores entrevistados, o que não se busca para categorizar "em padrões pedagogicamente aceitos ou reprovados, porque se assim eu o fizesse não estaria preocupada com indícios, mas com resultados" (p. 62). A busca, segundo essa autora, é por compreender "esse movimento entre sujeitos, contexto, relação e subjetividade" (p. 63). Em relação às situações narradas pelos professores entrevistados e que eram conhecidas por ela enquanto docente, a autora diz que se identificava estando frente a algumas dessas falas, mas que também havia uma diferenciação que marcava os lugares de professora e pesquisadora.

Do que afirma a autora acerca dessa identificação/diferenciação com o conteúdo das falas dos professores que entrevistou, cabe considerações sobre os saberes docentes e sua constituição. Tardif (2007) afirma os saberes docentes como plurais, constituídos, em parte, pelas experiências do professor, e também como saberes vindos da própria profissão. Por isso são, por um lado, saberes em contínua transformação, contemporâneos e contextualizados, mas também saberes tradicionalmente aceitos e que poucas mudanças apresentam. Uma vez que são saberes profissionais, em parte são universais, em parte são particulares.

Para Mota (2005), outra pesquisadora que também discutiu a questão dos saberes e conhecimentos docentes, é no exercício da reflexão sobre a docência que professores podem reelaborar e compreender melhor seu fazer e, nesse sentido, da construção desses saberes e conhecimentos, compreende-se a formação profissional como processo que articula os

\footnotetext{
${ }^{6}$ CALVINO, I. O castelo dos destinos cruzados. São Paulo: Companhia das Letras, 2001.
} 
conhecimentos adquiridos e a experiência da docência, o que está em contínua mudança. Nesse sentido, podemos pensar na constituição de saberes de um grupo profissional e também de saberes de sujeitos específicos e que atuam em realidades distintas. Há, portanto, nessa definição de saberes docentes tanto a identificação como a diferenciação entre os saberes de distintos profissionais, como já afirmou Tobias (2015). A percepção dessas semelhanças e dessemelhanças implica no reconhecimento de uma relação alteritária entre esses profissionais.

Em relação à alteridade dialogamos com Amorim (2001), cujos estudos têm referência em Bakhtin $(1970 ; 1975 ; 1981 ; 1982 ; 1987) .{ }^{7}$ Esta pesquisadora afirma que a percepção da alteridade aquilo que se produz entre o pesquisador e o outro - como instância promotora de outras e novas possibilidades, é o que dá riqueza aos encontros e o que nos estimula à partilha. Segundo a autora, “o outro aqui é o interlocutor do pesquisador. Aquele a quem ele se dirige em situação de campo e de quem ele fala em seu texto" (AMORIM, 2001, p. 22). Ouvir o outro exige abrir-se ao diálogo e, estando o pesquisador "no país do outro" (p. 23), carregando as marcas do seu estrangeirismo (também nos modos de escrita que traz na bagagem), faz-se necessário conhecer e reconhecer esse outro representado e presente nas formas de linguagem e nos seus outros modos de ser e estar, o que, à princípio, é estranho e estrangeiro ao pesquisador.

Para Amorim (2001), o pesquisador "abandona seu território, desloca-se em direção ao país do outro, para construir uma determinada escuta da alteridade, e poder traduzi-la e transmiti-la" (p. 26). Em se tratando de pesquisa educacional, talvez o desafio do pesquisador seja reconhecer essas outras formas de ser, atuar, falar e escrever. Pisar nesse terreno delicado do estrangeiro, estando na escola com os professores, implica trilhar o espaço do "entre", do que se mistura e mescla.

Outro aspecto a se considerar na relação da pesquisadora com as professoras é o campo em que esse encontro acontece, a saber, a educação escolar e a escola. Estando na escola, pesquisador e professores vivenciam um território constituído de muitos saberes e conhecimentos, também corroborando sua própria bagagem. A escuta alteritária dos saberes do outro podem criar um espaço/tempo de reflexões. Quando o pesquisador se apropria das palavras outras do professor e as faz suas (BAKHTIN, 2003), saberes e conhecimentos são assumidos e (re)construídos por ambos os

\footnotetext{
${ }^{7}$ Para M. Bakhtin (Rússia, 1895-1975) os participantes dos processos de comunicação, a saber, o falante/escrevente e seus interlocutores, estão, no momento do diálogo, imersos em um mesmo contexto discursivo, o que possibilita o estabelecimento do diálogo. Porém, seus discursos são produzidos a partir das referências que trazem cada um dos sujeitos, mas, no diálogo, essas diferentes bagagens e saberes poderão encontrar-se e sentidos outros serão (re)construídos na partilha. Desse autor, em "O pesquisador e seu outro", obra de 2001 a que fazemos referência, Amorim faz uso das seguintes obras: La poétique de Dostoievski (1970), Esthétique et théorie du roman (1975), Marxismo e filosofia da linguagem (1981), Esthétique de La création verbale (1982) e A cultura popular na idade média e no renascimento (1987).
} 
participantes e, na confluência dos discursos, outros sentidos podem emergir. Chaluh (2008) afirma que estar na escola requer atenção às pistas e indícios, ${ }^{8}$ é preciso encontrar-se consigo mesma e com o outro, atenta ao que se passa, e ao que nos passa, como diz Larrosa (2004), para "construir e a desenvolver uma outra forma de conhecer a escola (não para constatar) pois são práticas que pretendem recuperar e dar visibilidade às preocupações e às inquietações dos sujeitos da escola" (CHALUH, 2008, p. 247).

Em relação às entrevistas, as reflexões se voltam à sua potencialidade como espaço/tempo de reflexão sobre as práticas docentes, situações das quais participam ativamente os sujeitos envolvidos - pesquisadora e professora, nessa pesquisa - e seus saberes e conhecimentos. Nesse sentido, da promoção de reflexões, é fundamental voltar-se à importância do estabelecimento de interlocução entre os participantes e, dentro disso, da implicação dos mesmos e de seus saberes e conhecimentos. As entrevistas narrativas vão ao encontro desses objetivos.

\section{ENTRE(VISTAS): FALANDO DAS EXPERIÊNCIAS DO ENSINAR}

É preciso explicitar que nessa pesquisa tanto o planejamento como o encaminhamento do processo de investigação como um todo se dirigiram por estudos teóricos acerca da temática da pesquisa - a saber, inclusão escolar, práticas de ensinar e formação docente -, bem como pelo próprio saber e conhecimento das pesquisadoras acerca dessa temática, ressaltando que a primeira autora do texto tem atuação como professora de alunos com deficiência intelectual e, portanto, experiências muito semelhantes às das professoras entrevistadas, embora se considerem as diferenças espaço/temporais entre sua atuação e a das docentes entrevistadas. Considera-se que tal experiência pôde contribuir no estabelecimento da interlocução com os entrevistados e possibilitou que as professoras participantes da pesquisa pudessem dizer e dizer-se sobre seu trabalho.

As entrevistas foram realizadas nas escolas onde atuavam essas professoras, em horário indicado pelas entrevistadas e tiveram duração que variou entre 45 e 60 minutos. Foram transcritas e analisadas tendo em vista os objetivos da pesquisa e o diálogo com os autores cujas idéias serviram de referência a essa investigação. Nessa análise buscou-se pela emergência de temas e subtemas que, em seu conjunto, responderam às principais questões de pesquisa, bem como promoveram que outras perguntas fossem feitas.

\footnotetext{
${ }^{8}$ Para dizer dos indícios que a pesquisa pode desvelar na escola, essa autora faz uso dos estudos de Ginzburg, do qual citamos GINZBURG, C. Sinais. Raízes de um paradigma indiciário. In: Mitos, emblemas, sinais. São Paulo: Companhia das Letras, 1989. p. 143-179.
} 
$\mathrm{Na}$ construção de uma escrita que apresentasse esse processo, buscando por uma imagem que representasse como as entrevistas foram concebidas e realizadas, entramos em contato com a obra "Olhares", disponível em website.

Figura 1. Olhares, obra de Elda Evelina.

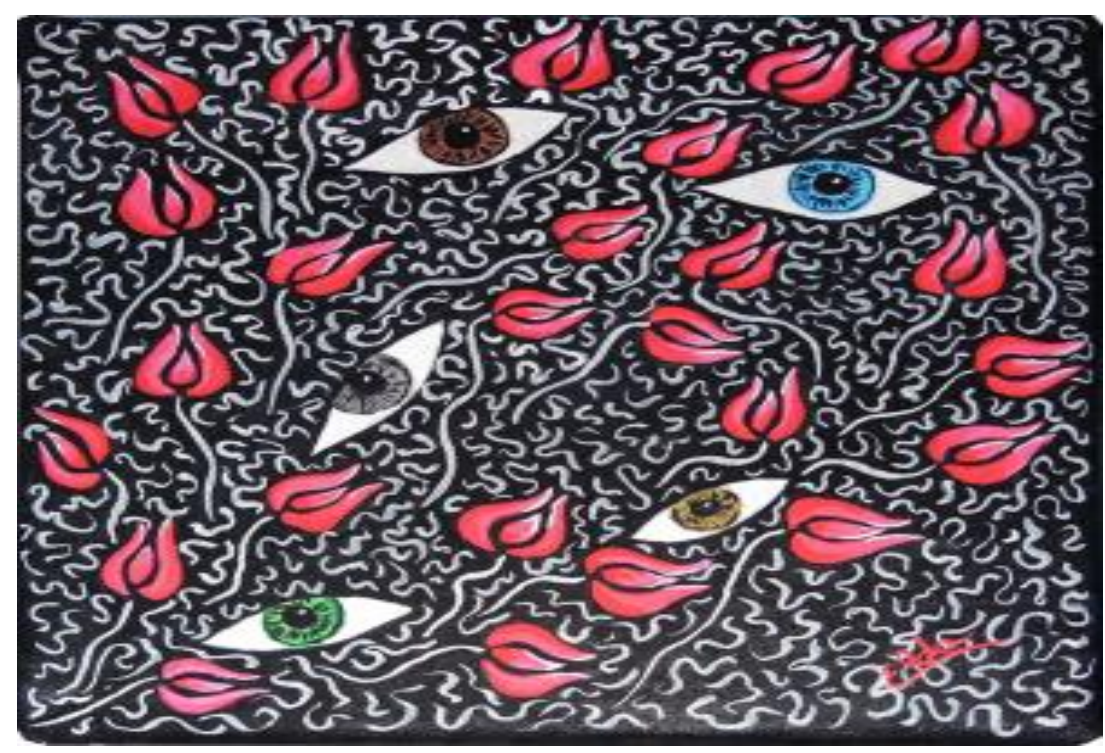

Fonte: foto de autoria da pintora disponível em <http://www.eldaevelina.com/obras/?p=1459>.

Além da obra em si interessou-nos também a explicação da própria autora acerca deste trabalho. A artista escreveu: "olhares a perscrutarem a seu redor, como que a procurar entender o que os cercam. [...] Os olhares não tão-somente vêem as formas, eles sentem o movimento e são por eles sensibilizados, resultando em uma dinâmica única” (ELDA EVELINA, s/d online).

Essa obra chamou nossa atenção pelo que indica a própria descrição da autora: "olhares a perscrutarem", a indagarem para compreenderem o que lhes cerca. É a partir dessa representação de olhares que se cruzam em (entre)vistas que podemos pensar no que se projetou para a entrevista: a ideia foi estabelecer diálogos e reflexões com as professoras, olhares partilhados acerca dos processos de escolarização e do ensino realizado para alunos que têm necessidades educacionais especiais.

\footnotetext{
${ }^{9}$ Olhares. In: Elda Evelina Obras. s/d. Disp.: 〈http://www.eldaevelina.com/obras/?p=1459>. Acesso: 28 jan. 2017.
} 


\section{PARTILHANDO HISTÓRIAS: O DOCENTE NO ENCONTRO COM O OUTRO - O ALUNO QUE TEM NECESSIDADES EDUCACIONAIS ESPECIAIS.}

As entrevistas tinham início com a narrativa da pesquisadora acerca de sua experiência, o que tinha como intenção convidar as professoras a também contarem sua história, bem como indicar a narrativa como o gênero a partir do qual se poderia construir aquela conversa.

Eu comecei a trabalhar em uma instituição de Educação Especial em 1985, porque quando eu me formei não havia nada para crianças com deficiências no ensino regular e, desde a formatura, em 1984, quis trabalhar nessa área. Trabalhei em instituição de ensino especializado por muitos anos e depois trabalhei em sala especial, o que, hoje, se estuda como uma fase, um período, dessa história. Era uma sala dentro da escola, mas totalmente separada. Ali eles colocavam meninos com diferentes deficiências e essa sala era totalmente à parte do restante da escola, sendo que até o recreio era em outro horário porque a escola entendia que essas crianças não podiam fazer parte da dinâmica escolar, nem as crianças e nem seus professores. Depois, mais recentemente com a inclusão escolar, eu tenho acompanhado esse processo, atualmente, mais recentemente ainda, pensando na formação dos professores. Eu dou aula no curso de Pedagogia em uma disciplina que se chama "Educação Inclusiva" e tenho procurado estudar essa área, pesquisar. Então hoje eu estou mais envolvida com a formação dos professores, e indiretamente com as crianças.

Pensando hoje na inclusão escolar, no que vocês estão construindo, a gente vê então que foi um longo processo porque eu vim de um momento que era impossível pensar na perspectiva de que uma pessoa com deficiência pudesse vivenciar os mesmos processos social e escolar que os demais. Eu acho que as coisas estão mudando, embora gradativamente. Essa pesquisa é para ouvir vocês sobre sua própria historia, sobre as impressões que vocês têm sobre a inclusão escolar. Então agora eu queria que você me contasse sua história com a inclusão escolar, contando quando foi a primeira vez que, no ensino regular, você teve um aluno que tinha necessidades educacionais especiais. Você lembra quando foi essa primeira vez? Pode me contar? (Trecho 1 da entrevista realizada com a Professora Marta, ${ }^{10}$ maio de 2016).

As professoras também contaram suas histórias e nesses relatos, fruto de uma memória, se pode perceber que o encontro com este novo aluno mobilizou as docentes, indo da resistência, em alguns casos, à busca de outro sentido para a prática pedagógica, em muitos outros. As histórias contadas pelas professoras disseram do processo de escolarização desses alunos e também revelavam fragilidades da própria organização escolar e do ensino realizado.

Pesquisadora: Marta me conta sobre a primeira vez que você recebeu um aluno que tinha necessidades educacionais especiais. O que você sentiu, qual foi sua impressão?

\footnotetext{
${ }^{10}$ Todos os nomes apresentados, de professores e alunos, são fictícios.
} 
Professora Marta: Foi a Mariana, no ano passado. Eu a conhecia de corredor e sabia as dificuldades dos professores em trabalhar porque, quando ela chegou, eu acho que ele nem tinha intérprete, não tinha conhecimento de Libras. Ela sabia comunicar soletrando algumas palavras.

Pesquisadora: Ela chegou em que ano aqui na escola?

Professora Marta: No sexto ano e continuou ate o ensino médio. Quando eu conheci a Mariana me falaram que ela não era nem alfabetizada, que ela copiava o que tinha no quadro. Aí eu comecei a questionar: "nossa, a menina não foi nem alfabetizada! O que ela fez na escola ate hoje?" Foi quando eu comecei a trabalhar com junto com a Intérprete dela. A Intérprete ensinava em Libras e eu em Língua Portuguesa.

Pesquisadora: Ela não tinha tido intérprete antes?

Professora Marta: Quando ela entrou aqui, creio que não. Acho que a interprete dela deve ter chegado quando ela tava no $8^{\circ}$ ano, ou alguma coisa assim. Eu sei que antes ela não tinha contato com Libras e, no ano passado, quando eu me deparei com a Mariana nós começamos esse trabalho. Embora eu ache que não seja o melhor trabalhar simultaneamente. Ela teria que ter Libras pelo menos como a primeira língua para, depois, eu tentar introduzir a Língua Portuguesa. Mas como a gente não tem estrutura nem tempo para isso, eu tive que trabalhar as duas línguas simultaneamente. (Trecho 2 da entrevista realizada com a Professora Marta; maio de 2016).

No documento "Guia de Orientação da Educação Especial na rede estadual de ensino de Minas Gerais" (MINAS GERAIS, 2014) há a indicação da necessidade do Professor Intérprete de Libras nas escolas e salas de aula. Porém, a história contada pelas professoras, nesse caso por Marta, indica que até recentemente esse profissional não estava nas escolas, realidade que vem sendo transformada, porém gradativamente. Em outro trecho da sua entrevista, apresentado na sequência, a professora Marta diz da invisibilidade que essa aluna tinha na escola.

Pesquisadora: Ela não era alfabetizada mesmo?

Professora Marta: Não, ela era uma ótima copiadora, ela copiava perfeitamente. Ela não conseguia entender o que ela escrevia, para ela não fazia sentido nenhum.

[...] Pesquisadora: Já que ela passou todo o ensino fundamental aqui na escola, você tem ideia de como ela era avaliada? Qual era a compreensão que ela tinha dos conteúdos?

Professora Marta: Na sala dela tem uma prima e estudam juntas. Antes, me parece, que em todas as avaliações ela sentava junto com a prima para concluir a avaliação. Então eu acho que ela só copiava a avaliação da prima.

Pesquisadora: A prima sabia Libras?

Professora Marta: Não. 
Pesquisadora: Então, mesmo que a prima tentasse ajudá-la, seria incompreensível.

Professora Marta: Sim, era o trabalho de copiar.

Pesquisadora: E ai você acha, então, que ela tem falhas de conteúdo.

Professora Marta: Sim, tem falhas de conteúdo. Eu creio que ninguém enxergou a Mariana até então. Porque ela chegar no ensino médio simplesmente copiando... (Trecho 3 da entrevista realizada com a Professora Marta; maio de 2016).

A fala de Marta diz do lugar social dado a esses alunos e alunas na escola que, na maioria dos casos, é o lugar daqueles que não são vistos e considerados. Porém, no processo de construção dos saberes da/na escola, quando professores e alunos se colocam como pares de um processo, há, nas brechas daquilo que está cristalizado, a possibilidade de construção de uma escola outra, o que provavelmente possibilitou à Marta enxergar sua aluna em suas necessidades e potencialidades, o que antes não havia acontecido com outros professores.

Para Sampaio (2007), ensinamos a partir de certezas que nos guiam e às nossas práticas, porém, muitas dessas certezas não se adéquam mais à realidade vivida por nós, professores,com os alunos, o que pode ser desvelado e transformado por processos reflexivos e partilhados. Especificamente acerca dos alunos que têm necessidades educacionais especiais, sua inclusão em classes comuns do ensino regular tem solicitado dos professores uma contínua reconstrução de seu fazer. Segundo Caiado (2008) requer a construção de propostas pedagógicas e currículos que tenham referência na concepção de que "o saber é vivo e a construção sistematizada é humana, em que os saberes dos alunos seriam o ponto de partida para dimensões que ampliassem a curiosidade e o prazer de conhecer e intervir no mundo" (p. 370).

Em “A inclusão dos professores na educação inclusiva", Fontana (2001) narra sua experiência com uma aluna cega e fala de sua própria cegueira, de seu "não saber como agir diante dessa diferença" (p. 8). Reflete sobre os modos como foi reconstruindo suas aulas a partir do que a própria aluna ia lhe sinalizando: "não se preocupe professora. Eu vou ensinando a você como devo fazer para me ensinar" (p. 4). Para a autora, é no encontro com o aluno (e no caso da inclusão escolar com um aluno que solicita um olhar diferenciado do professor) que os docente podem, na construção da alteridade, se rever, olhando-se nessa relação. Nesse processo, narrar a própria história parece ser o disparador de reflexões e de um movimento formativo para os docentes.

Nesse mesmo sentido, consideramos que em uma pesquisa, na relação entre pesquisador e professores participantes, saberes e conhecimentos são reconhecidos e reconstruídos pelo professor/na presença do outro, nesse caso, do pesquisador, e em situações de interação. A leitura analítica das entrevistas sugere que essa interação esteve presente nas entrevistas realizadas; 
também se considera, nessa interação, a presença dos saberes e conhecimentos da pesquisadora que, partilhados, são também alargados com as novas experiências.

\section{SABERES E CONHECIMENTOS EM (TRANS)FORMAÇÃO: A PESQUISADORA}

Da mesma forma que acontece com os professores, compreendemos que os pesquisadores, no movimento da própria pesquisa, estando com o outro, também se (trans)formam (CHALUH, 2008). Na pesquisa realizada, uma vez que uma das pesquisadoras também atuou como professora de alunos que tinham necessidades educacionais especiais, o conhecimento e os saberes da pesquisadora tiveram lugar na construção da entrevista. Porém, aos saberes e conhecimentos anteriores da pesquisadora, se acrescentaram outros/novos sobre cada contexto escolar onde a entrevista era realizada.

Nesse sentido, merece destaque o fato de que o (re)conhecimento da pesquisadora acerca de cada contexto escolar ampliou seus saberes e conhecimentos e também participou do estabelecimento das reflexões que aconteceram nas entrevistas. Compreendendo-se a leitura da realidade como fruto da percepção do pesquisador, se considerou nessa leitura o resultado advindo de diferentes procedimentos e instrumentos de pesquisa, entre os quais o diário de campo e o diário fotográfico $^{11}$ construídos pela pesquisadora e compreendidos como importantes meios para a construção de um conhecimento sobre a escola, além do que se promoveu nas entrevistas.

A apresentação de algumas imagens na sequência objetivou evidenciar aspectos que foram compreendidos pelo olhar - "olhares a perscrutarem a seu redor, como que a procurar entender o que os cercam..." (ELDA EVELINA, s/d online) -, o que permitiu ampliar a percepção e as reflexões da pesquisadora sobre o que disseram as professoras durante as entrevistas.

\footnotetext{
${ }^{11}$ Para Bogdan e Biklen (1994, p. 150), os diários são o instrumento em que o pesquisador registra notas sobre "o que ouve, vê, experiência e pensa no decurso da recolha e reflexão sobre os dados de um estudo qualitativo". Sobre o registro de observações, Lüdke e André (1986, p. 32) afirmam que o pesquisador deve encontrar "um momento propício para fazer as anotações, que não seja muito distante doseventos observados, para não haver esquecimento, nem provoque dúvidas nos participantes sobre sue verdadeiro papel". Quanto ao uso de fotografias na pesquisa qualitativa, Pletsh e Rocha (2014) diz do seu emprego como uma das fotes ou documentos que compõem a pesquisa; já Loizos (2008) define a fotografia como método visual próprio da pesquisa social.
} 
Figura 2. Fotos de contextos escolares
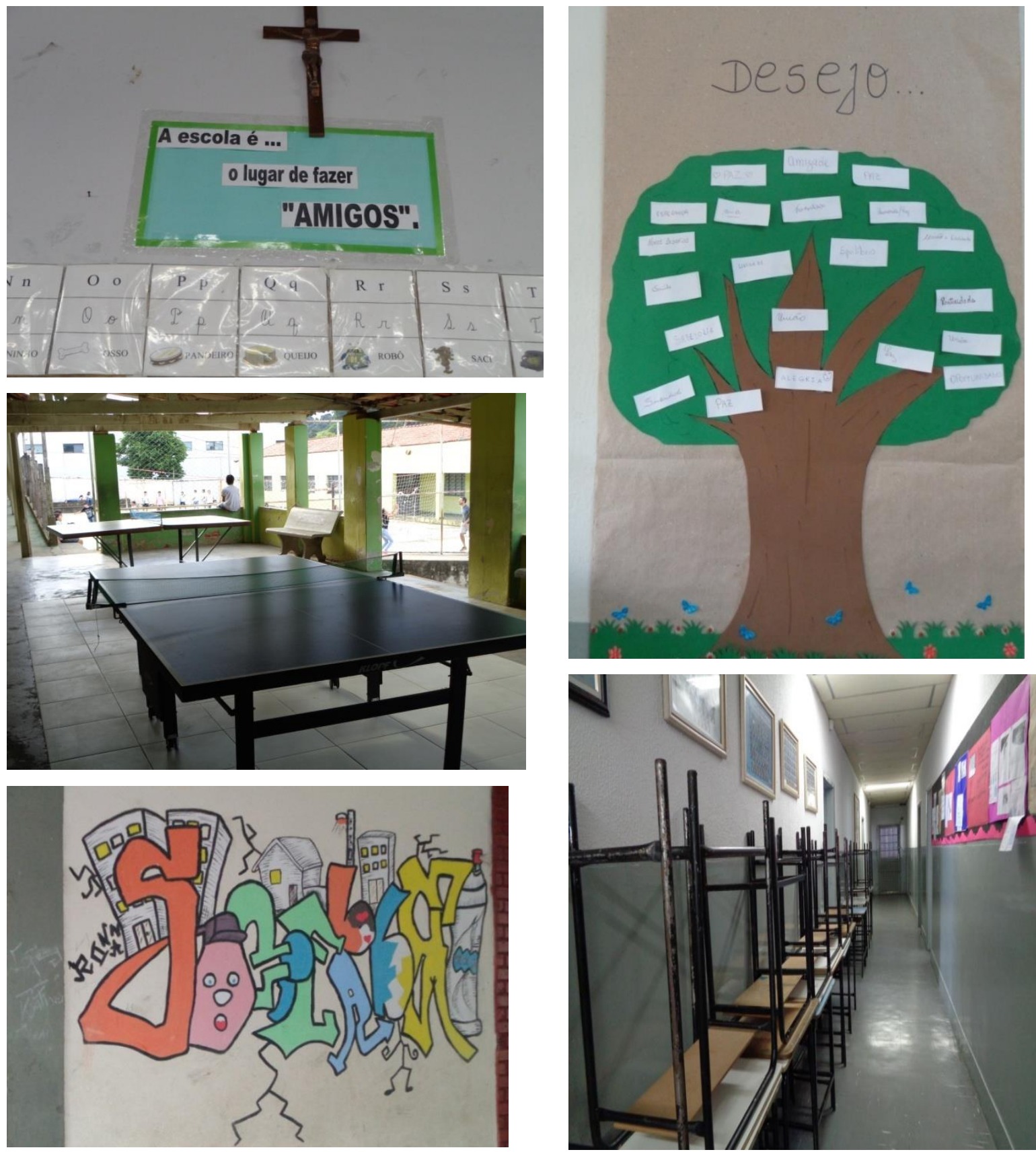

Fonte: acervo das pesquisadoras; diário fotográfico da pesquisa. ${ }^{12}$

Os registros escritos e fotográficos mostraram que a sala de aula tem um entorno e a escola também se faz nas reuniões, no lanche dos professores, na comemoração do Dia das Mães e Dia das Mulheres, nos cartazes afixados nos quadros de avisos, na memória viva e presente nos prédios e mobiliários, e nas muitas imagens religiosas que indicam, entre muitos dos aspectos que caracterizam essas instituições, que a religiosidade é um aspecto presente no cotidiano e na cultura escolar. O diário fotográfico e os diários de campo possibilitaram a construção de um tecido

\footnotetext{
${ }^{12}$ São parte do diário fotográfico construído durante a pesquisa, em diferentes escolas.
} 
discursivo sobre a escola, o ensino e os professores. Esses registros possibilitaram ampliar o olhar para além das entrevistas, mas sempre buscando por estabelecer relação entre o que se conhecia por meio desses diferentes instrumentos e procedimentos.Visando contar mais, apresentamos na sequência outra das entrevistas.

\section{SOBRE (IM)POSSIBILIDADES E AMANHÃS}

No trecho apresentado na sequência, da entrevista com Jane, professora de Educação Física, a docente contou sobre suas aulas para uma turma na qual estavam dois alunos com deficiência visual, mostrando como ensinava basquete para esses alunos. Na entrevista, a professora disse sobre seu conhecimento e saber sobre os alunos e de como chegou a essa prática e, durante a entrevista, a relação entre o ensino individualizado e para o grupo aparece na fala da professora. Sobre tal aspecto, Sacristán (1998) diz da necessidade de uma gestão de ritmos de aprendizagem e de interesses, o que o desenrolar dos acontecimentos, após a entrevista, parece ter revelado. Segue trecho dessa entrevista.

Pesquisadora: Me fale então desse aluno e do seu trabalho com ele.

Professora Jane: Você tem que ver ele jogando basquete! A percepção sensorial dele... Tipo “agora você vira um pouquinho para a direita, agora para a esquerda, agora coloca um dos pés um pouquinho para frente e vai flexionar os joelhos e impulsionar a bola para frente. Vai fazer uma parábola. A bola vai sair da sua mão e vai cair lá na cesta”.

Pesquisadora: Como a gente está gravando eu tenho que dizer que você pegou a minha mão e fez um movimento, demonstrando. E eu entendi exatamente o que você queria que eu fizesse.

Professora Jane: Dá para entender, não dá? Se você enxerga e eu fizer assim [a professora repete movimento no braço da pesquisadora], eu vou demonstrar. Se eu pegar uma pessoa que não é deficiente visual e mostrar com a minha mão como é movimento....” Vai apoiar essa mão, a outra vai colocar em baixo e vai impulsionar essa mão para cima. Vai dobrar o joelho"... Porque para o aluno a gente não fala "vai flexionar". O Pedro ${ }^{13}$, para mim, no meu pouco conhecimento, ele é autodidata porque não tem nada que ele não aprenda.

[...] Pesquisadora: E como você descobriu o basquete?

Professora Jane: Eu pego bolas diferentes que eu tenho lá e então eu comecei com uma bola menor, para ele passar a bola de uma mão para a outra. Porque a Débora disse que eles têm muita dificuldade. O Pedro, principalmente, ele tinha muita dificuldade de jogar a bola de uma mão para outra, mesmo tendo o guizo dentro da bola. Porque aqui na sala de recurso tem a bola com guizo, mas eu nem levo para lá porque eu tenho medo de sujar, estragar....Ai ela falou $[a$

\footnotetext{
${ }^{13}$ Como já dissemos, os nomes de alunos e professores são fictícios.
} 
professora se refere à Débora, a professora da Sala de Recursos]: "uma ideia que eu posso te dar é você trabalhar isso porque eles têm dificuldade. Até de passar a bola de uma mão para outra eles têm dificuldade. Porque eu fazia isso com o Marcos no ano passado.

Pesquisadora: O Marcos tem deficiência visual também?

Professora Jane: O Marcos estava no quinto ano; eu dava aula no quinto e pegava o Marcos para trabalhar com ele. E aí eu fiz isso com a Ana - a Ana e o Pedro são os alunos deficientes visuais com quem eu trabalho - e funcionou. A Ana consegue passar por trás do corpo e pegar com a outra mão, pegar com uma mão e outra e colocar a bola em cima da cabeça e volta com mais destreza, facilidade. Já o Pedro eu fiquei impressionada. "Você fazia este exercício antes? Ah, eu não gostava”. E ai ele, sabe, fiquei feliz porque comigo ele está fazendo. E comecei a trocar as bolas. Comecei com uma bola menor, com uma bola de vôlei, e aí eu fui trocando as bolas. [...] A Ana já não tem essa facilidade de jogar a bola, mas ela faz.

[...] A sala deles adora jogar queimada, eles adoram. Ai quando eu quero premiar eles eu dou queimada. Ai participa o Fernando; ele tem deficiência múltipla. Ele chegou aqui cadeirante e hoje ele corre que nem um louco naquela quadra! Chuta bola, joga, tudo. O que eu der para ele vai jogar. E participam o Pedro e a Ana. E eles não enxergam para correr atrás da bola.

[...] Pesquisadora: Então, assim, como você consegue dar essa orientação para o Pedro em uma turma de 20 alunos, sendo três alunos com necessidades educacionais especiais? Onde é que os demais estavam?

Professora Jane: São 19; três que têm necessidades educacionais especiais. Eu estava com ele de um lado da quadra enquanto os outros alunos que enxergam estavam fazendo a atividade do outro lado da quadra. A Ana estava do meu lado, fazendo a mesma coisa, e mais a Professora de Apoio $^{14}$, que realmente apóia. Só que eu acho assim.... Ah, dá para trabalhar uma Apoio e três alunos. Mais ou menos, dá sim. Mas para um trabalho diferenciado tem que ter essa Apoio mesmo. (Trecho 1 da entrevista realizada com a Professora Jane; abril de 2016, os acréscimos são nossos)

O relato diz de uma professora que descobre o basquete com os alunos e os ensina a jogar. A fala da professora indica o caminho trilhado para construir o trabalho com seus alunos; traz a dinâmica com o grupo, a presença da Professora de Apoio, o como organiza o tempo para atender os alunos que têm necessidades educacionais especiais e os demais, o que tem se mostrado como um desafio para todos os professores. Também chamou a atenção na entrevista outros aspectos,

\footnotetext{
${ }^{14}$ Em Minas Gerais, segundo o Guia de Orientação da Educação Especial na rede estadual de ensino de Minas Gerais (MINAS GERAIS, 2014), os alunos com deficiência e/ou transtornos globais do desenvolvimento, matriculados em escolas regulares comuns, poderão necessitar do Professor Intérprete de Libras, do Professor de Apoio à Comunicação, Linguagem e Tecnologias Assistivas e do professor Guia-Intérprete (p. 19 e 20). O chamado Professor de Apoio (no caso da entrevista, para alunos com deficiência visual) "visa favorecer o acesso do aluno à comunicação, ao currículo, por meio de adequação de material didático-pedagógico, utilização de estratégias e recursos tecnológicos" (p. 20-21); deve atuar de forma colaborativa com os professores da classe comum.
} 
como o fato de que a professora não usa a bola com guizos para não sujar, mas a evidência maior foi o trabalho, a prática realizada com os alunos com deficiência visual.

Porém, cerca de duas semanas depois, no retorno a essa mesma escola para a realização de outra entrevista, a pesquisadora encontrou Jane e sua impressão foi de que parecia tratar-se de outra professora. O desânimo e o desencanto a definiam naquele segundo encontro; ela relatou seus motivos. Essa situação foi registrada no diário de campo.

Após algumas semanas da realização da entrevista com a professora Jane, retorno à escola para a entrevista com outra professora. Enquanto espero, me dirijo à sala dos professores e ali encontro Jane. Cumprimentei-a animadamente, mas percebi algo de diferente na sua reação. Perguntei-lhe então sobre seus alunos e o trabalho com o basquete e a professora pareceu desabar. Contou-me que os alunos tinham procurado a direção da escola e dito que ela, com o basquete, os afastava das outras atividades com os colegas de turma. Disseram para a diretora que não mais queriam realizar essa atividade diferenciada. Segundo os alunos afirmaram, preferiam jogar queimada e se esbarrar nos colegas, do que estar afastado deles. Frustrada em sua iniciativa, decepcionada com a atitude dos alunos, perdida, a professora chegou a mencionar que estava desistindo da inclusão, ou de buscar práticas pedagógicas que fossem ao encontro das necessidades dos alunos. Ponderei com ela sobre o que entendia que tinha acontecido e questionei acerca da atitude dos alunos: possivelmente, sua história de exclusão os levara a agir da forma como o fizeram. E, provavelmente, o receio da reação da professora não tinha lhe permitido falar diretamente com ela. Pareceu-me, disse à professora, que falar com a diretora foi mais fácil para eles do que enfrentá-la. Eram adolescentes, também. E que professora teria recursos para lidar com aquela situação. Mas ela foi irredutível: disse da sua decepção, não aceitou minha solicitação de dar continuidade à entrevista, e não mais falou comigo nas semanas e meses que se sucederam, apesar de minha tentativa de estabelecer outros contatos. O que fica é seu silêncio e ausência (tão diferente da sua fala solta e alegre na entrevista) e o que esses insistem em me dizer. Minha experiência como professora me grita. Diz que a inclusão escolar, ainda em construção, precisa ser mais refletida e compreendida por todos, no que também implica em assistir e atender os professores em suas experiências com esses alunos. (Trechos do Diário de campo, maio de 2016).

Diante disso, ao escrever esse texto, nossas reflexões se voltam, em primeiro lugar, a como deve estar hoje a professora, como reagiu a essa experiência e o que tem construído com seus novos alunos, porque de fato entendemos que outros alunos e situações deverão mobilizar naquela professora o que ficou silenciado nela, mas que ainda está latente. Compreendemos que outras experiências dar-se-ão a partir daquela, em um fluxo contínuo de reconstruções e, apesar do desencanto da professora naquele momento, compreendemos que essa situação vivida com os alunos poderá ser reconhecida pela professora como uma experiência, no sentido daquilo que a tocou e que, a partir desse toque, pode promover reflexões e mudanças (LARROSA, 2004). 
Em relação a uma (des)construção, o que possivelmente ocorreu com essa professora, consideramos que afetar-se pelo que lhe/nos dizem os alunos pode ser encarado pelo professor como promotor de mudanças, ou de paralisação; também é preciso considerar, por outro lado, que esse é um processo de desconstruções, nem sempre tranquilo em função de sua complexidade (MOTA, 2005).

Outra reflexão a partir da fala de Jane no trecho anterior se refere à própria realização da entrevista e à ideia de interação afirmada por Bakhtin (2004). Nesse sentido, uma vez que compreendemos, como ensina este autor, que nossas palavras são sempre atravessadas pela palavra do outro, podemos afirmar que naquele momento da entrevista, juntamente com Jane, nos voltamos para alguns aspectos de prática dessa professora que, naquela situação, acabaram por caracterizar o contexto-cena em que essa prática era realizada. Porém, ao retornarmos à escola, reencontramos a professora que nos contou o que havia acontecido, o que alargou nossa percepção e pudemos compreender de forma mais ampla acerca de, por exemplo, a relação desses alunos consigo mesmo, com os demais e com a própria Jane, o que se evidenciou na queixa levada à direção e que sugeria fazer relação com um lugar socialmente dado e de outro (lugar) assumido por eles.

Também nos reportamos mais uma vez ao diário de campo e às imagens registradas na escola, naquela e nas demais. Dados como a presença de recursos específicos somente na Sala de Recursos, espaços e ambientes sem adaptação arquitetônica e salas numerosas contribuíram para ressignificar a cena, e para refletirmos sobre o que nos disse a professora na entrevista, e depois dela, tendo também como referência esses outros elementos. Nesse sentido, indicamos a importância de que, em uma pesquisa, diferentes elementos sejam considerados na construção dos saberes sobre a escola, os professores e seus alunos. A ideia é que um instrumento de pesquisa, nesse caso a entrevista, precisa complementar-se a partir de outros procedimentos e instrumentos.

Reiteramos ainda, nesse processo, sobre a ampliação dos saberes e conhecimentos da pesquisadora (e aqui, com Tardif [2007], nos referimos aos saberes disciplinares, profissionais, da ciência da educação, bem como, e principalmente, aos saberes da experiência) estando na escola e se colocando, em interação, aberta a olhar e ao olhar do outro, o que, no caso da pesquisa apresentada, colocou em movimento e ampliou o que sabia a pesquisadora. 


\section{CONSIDERAÇÕES}

No contexto de construção de uma educação que seja realmente inclusiva, os professores vêm reconstruindo suas práticas de ensinar tendo em vista alunos que têm necessidades educacionais especiais. O que contaram as docentes entrevistadas indica, porém, que esse processo não tem acontecido sem as contradições próprias a toda transição. Nos excertos das entrevistas aqui apresentados se podem perceber as contradições e buscas cotidianamente vividas por essas professoras. Se hoje ainda se constroem formas de atuação e ensino que não se podem caracterizarse como práticas que efetivamente atendam aos princípios de uma educação inclusiva, essas práticas também dizem de um processo já iniciado em que as mudanças acontecerão promovidas pelas solicitações dos próprios contextos e sujeitos envolvidos, alunos e professores. Fontana (2001) e Sampaio (2007) afirmam a importância de processos de reflexão, individual e coletiva, na reconstrução de saberes e conhecimentos sobre a docência e o ensino, o que se faz fundamental na inclusão escolar em que certezas não se adéquam mais à realidade e à contemporaneidade.

Em relação às entrevistas, no que este texto apresenta, no que se deu no diálogo entre cada professora e a pesquisadora, esse diálogo pode ser considerado como reflexivo se tomarmos o espaço/tempo da entrevista como o de construções de tramas sociais e discursivas. Ao responderem à pesquisadora, as professoras respondiam também a si próprias e, assim entendemos, que responder ao outro (um outro implicado no processo) pode levar o sujeito a ouvir-se a si próprio. Na perspectiva de uma narrativa (MEIRELES, 2015), a construção das entrevistas evidenciou interações que se produziram entre a professora e a pesquisadora, que tinham experiências docentes comuns com alunos com necessidades educacionais especiais. Também diz de saberes reafirmados e/ou ressignificados a partir do olhar do outro, estrangeiro ao nosso próprio saber e conhecimento. Nesse sentido, se consideram os saberes e conhecimentos dos pesquisadores como elementos que também participam das entrevistas e que também podem ser (trans)formados nos olhares - da pesquisadora e das professoras - que se cruzam "a perscrutarem". Nesse sentido, podemos afirmar sobre uma entrevista narrativa implicada, da qual participam sujeitos, saberes e conhecimentos em interação e que se ampliam a partir de diferentes olhares, estendendo-se a outros saberes e conhecimentos sobre a escola e os professores. 


\section{REFERÊNCIAS}

AMORIM, M. O pesquisador e seu outro: Bakhtin nas ciências humanas. São Paulo: Musa Editora, 2001.

BAKHTIN, M. Os gêneros do discurso. In: Estética da criação verbal. 4. ed. São Paulo: Martins Fontes, 2003. p. 261 306.

; VOLOCHINOV, V. N. Marxismo e filosofia da linguagem. 11. ed. São Paulo: Hucitec, 2004.

BOGDAN, R.; BIKLEN, S. Investigação qualitativa em Educação. Porto: Porto Editora, 1994.

BRASIL. MEC/SEE.Política Nacional de Educação Especial na Perspectiva da Educação Inclusiva. Brasília: MEC/SEESP, 2008. Disp.: 〈http://portal.mec.gov.br/seesp/arquivos/pdf/politica.pdf>.Acesso em: 10 jan. 2017.

CAIADO, K.R.M. Práticas pedagógicas: a diversidade na escola inclusiva. In: PERES, E.; TRAVERSINI, C.; EGGERT, E.; BONIN, I. (Org.). Trajetórias e processos de ensinar e aprender: sujeitos, currículos e cultura. Porto Alegre: EDIPUCRS, 2008. v. 03, p. 361-375.

CHALUH, L. N. Formação e alteridade: pesquisa na e com a escola. Tese (Doutorado em Educação) - Faculdade de Educação, Universidade Estadual de Campinas, Campinas, 2008.

ELDA EVELINA. Olhares. In: Elda Evelina Obras. s/d. Disp.: <http://www.eldaevelina.com/obras/?p=1459>. Acesso em: 28 jan. 2017.

FONTANA, R. C. A inclusão dos professores na educação inclusiva. ANPED. Anais da 24. Reunião... GT 15 Educação Especial. Caxambu. 2001.

GASKELL, G. Entrevistas individuais e grupais. In: BAUER, M.; GASKELL, G. Pesquisa qualitativa com texto, imagem e som. Um manual prático. 7. ed. Petrópolis: Vozes, 2008. p. 64 -89.

JOVCHELOVITH, S.; BAUER, M. W. Entrevista narrativa. In: BAUER, M.; GASKELL, G. Pesquisa qualitativa com texto, imagem e som. Um manual prático. 7. ed. Petrópolis: Vozes, 2008. p. 90 -113.

LARROSA, J. Notas sobre a experiência e o saber da experiência. In: GERALDI, C. M. G.; RIOLFI, C. R.; GARCIA, M.F. (Orgs.). Escola Viva: elementos para a construção de uma educação de qualidade social. Campinas, SP: Mercado de Letras, 2004. p. 113-132.

LOIZOS, P. Vídeo, filme e fotografias como documentos de pesquisa. In: BAUER, M.; GASKELL,G. Pesquisa qualitativa com texto, imagem e som. Um manual prático. 7 ed. Petrópolis: Vozes, 2008. p. 137-155.

LÜDKE, M.; ANDRÉ, M. E. A. Pesquisa em Educação: abordagem qualitativa. São Paulo: EPU, 1986.

MEIRELES, M. M. Entrevista narrativa e hermenêutica de si: Fonte de pesquisa (Auto)Biográfica e perspectivas de análises. In: SOUZA, E.C. (Org.). (Auto)Biografias e documentação narrativa: Redes de pesquisa e formação. Salvador: EDUFBA, 2015, p. 285-296.

MINAS GERAIS. Secretaria de Estado de Educação. Guia de Orientação da Educação Especial na rede estadual de ensino. Belo Horizonte, dez. 2013b. Disp. <http://seeensinoespecial.educacao.mg.gov.br/index.php?option=com

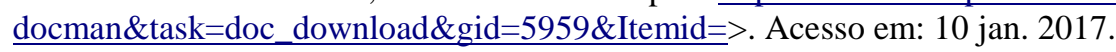

MOTA, E.A.D. Saberes e conhecimentos docentes: experiências da formação e experiências da profissão. Dissertação (Mestrado em Educação) - Faculdade de Educação, Universidade Estadual de Campinas, Campinas, 2005.

PLETSCH, M. D.; ROCHA, M.G.S. A etnografia como abordagem metodológica em pesquisa na educação especial. In: NUNES, L.R.O.P. (Org.). Novas trilhas no modo de fazer pesquisa em Educação Especial. São Carlos: Marqueizine \& Manzini; ABPEE, 2014.p.73-89.

SACISTÁN, G. A diversidade e o currículo comum: respostas políticas, organizativas e didáticas. In: PÉREZ GOMES, A. I.; SACRISTÁN, G. Compreender e transformar o ensino. 4. ed. Porto Alegre: Artmed, 1998. p. 186 -191.

SAMPAIO, C.S. A formação da professora-pesquisadora no diálogo prática-teoria-prática. In: VARANI, A; FERREIRA, C.R.; PRADO. G.T. Narrativas docentes: trajetórias de trabalhos pedagógicos. Campinas: Mercado das Letras, 2007.p. 247-260.

TARDIF, M. Saberes docentes e formação profissional. 8. ed. Petrópolis: Vozes, 2007.

TOBIAS, J.K. Saberes da docência pelo olhar dos docentes. Dissertação (Mestrado em Educação) -Unesp. Rio Claro. 2015. 


\section{RESUMO}

A pesquisa, realizada com professores do ensino fundamental que atuam em escolas estaduais localizadas em municípios do sul de Minas Gerais, teve como foco as questões que emergem da matrícula no ensino regular de alunos que têm necessidades educacionais especiais. Este texto, um recorte da referida pesquisa, discute as entrevistas realizadas. Na perspectiva de narrativas, pondera sobre as entrevistas como situações de reflexões e evidencia as tramas construídas por meio da interação estabelecida entre pesquisadora, professoras e seus saberes e conhecimentos. Considera-se que a interação estabelecida, a partir dos lugares de pesquisadora e professora, se mostra profícua na promoção de reflexões que podem possibilitar a (re)construção dos saberes docentes.

Palavras-chave: interação; saberes; entrevistas narrativas.

\section{INTERVIEW: FROM IMPLICATION TO LEARNING AND KNOWLEDGE ON TEACHING AND SCHOOL INCLUSION}

\section{ABSTRACT}

The research, carried out with primary school teachers who work in state schools located in municipalities in the south of Minas Gerais, focused on the issues that arise from enrollment in regular education of students who have special educational needs. This text, a cut from this research, discusses the interviews conducted. In the perspective of narratives, she ponders on the interviews as situations of reflections and shows the plots constructed through the established interaction between researcher, teachers and their learning and knowledge. It is considered that the established interaction, from the places of researcher and teacher, proves fruitful in the promotion of reflections that can make possible the construction of the teaching knowledge.

Keyword: interaction; learning; narrative interviews. 